\title{
ANALISA KEBUTUHAN PLATFORM PENDORPOWERMASSAGE.ID SEBAGAI SOLUSI BAGI PARA LULUSAN SARJANA PENDIDIKAN KEPELATIHAN OLAHRAGA
}

\section{ANALYSIS OF PENDORPOWERMASSAGE.ID PLATFORM NEEDS AS A SOLUTION FOR BACHELORS GRADUATE OF SPORT TRAINING EDUCATION}

\section{Fekie Adila1 ${ }^{*}$, Rivan Saghita Pratama², Ni Putu Nita Wijayanti3 ${ }^{3}$ Oca Fernandes AF4, Mohammad Muhibi ${ }^{5}$, Ricky Fernando ${ }^{6}$}

1,3,4Pendidikan Kepelatihan Olahraga, Fakultas Keguruan dan Ilmu Pendidikan, Universitas Riau, Indonesia

2Pendidikan Kepelatihan Olahraga/Fakultas Ilmu Keolahragaan, Universitas Negeri Semarang, Indonesia

${ }^{5}$ CEO Klinik Massage Seger Waras, Kota Semarang, Indonesia

6Pendidikan Jasmani Kesehatan dan Rekreasi, Fakultas Keguruan dan Ilmu Pendidikan, Universitas Islam Riau, Kota Pekanbaru, Indonesia

*Corresponding Author: Fekie Adila, fekie.adila@lecturer.unri.ac.id

Received: 2021-05-02; Revised: 2021-05-04; Accepted: 2021-06-18

\begin{abstract}
Abstrak
Prospek peluang kerja yang dimiliki oleh mahasiswa program studi pendidikan kepelatihan olahraga cukup menjanjikan antara lain pelatih, private trainer, instruktur olahraga, sport terapis, manajer lembaga atau klub olahraga, sport event organizer, dan tenaga pendidik jasmani. Akan tetapi hal ini berbanding terbalik di lapangan, banyak alumni lulusan S1 Pendidikan kepelatihan olahraga bekerja tidak sesuai bidangnya. Penelitian ini bertujuan untuk mengetahui kebutuhan lulusan S1 pendidikan kepelatihan olahraga Universitas Riau terhadap pengadaan platform pendorpowermassage.id. Metode penelitian yang digunakan adalah metode deskriptif. Subjek yang terlibat dalam penelitian ini berjumlah 24 orang yang diambil dari 20 persen dari jumlah total mahasiswa Pendidikan kepelatihan olahraga angkatan 2016. Pengumpulan data menggunakan google form. Analisis data menggunakan statisitik deskriptif. Hasil dari penelitian ini subyek membutuhkan lapangan pekerjaan setelah lulus kuliah; subyek siap terjun ke lapangan untuk menjadi masseur dan menangani cidera; subyek butuh aplikasi untuk sport massage, subjek memerlukan standarisasi dan training dari penyedia platform pendorpowermassage.id massage; subjek memerlukan adanya standarisasi harga jasa massage dari penyedia platform. Kesimpulan dari penelitian ini menyatakan bahwa perlunya pengadaan platform pendorpowermassage.id pada program studi pendidikan kepelatihan olahraga dengan tingkat persentase yang diinginkan adalah sebesar $89 \%$.
\end{abstract}

Kata Kunci: bisnis, olahraga, massage, masseur

\begin{abstract}
The prospect of job opportunities owned by students of the Sports Coaching Education Study Program is quite promising, including coaches, private trainers, sports instructors, sports terapiss, managers of sports institutions or clubs, sport event organizers, and physical educators. However, this is inversely proportional to the field, many alumni who graduate from the Sports Coaching Education S1 work not in their respective fields. This study aims to determine the needs of graduates of the University of Riau Sports Coaching Education for the procurement of the pendorpowermassage.id Platform. The method used is descriptive method. Subjects involved in this study amounted to 24 people taken from 20 percent of the total number of students of Sports Coaching Education class 2016. Data collection using a google form questionnaire. Data analysis used descriptive statistics. The results of this study the subject requires employment after graduating from college; subjects are ready to go into the field to become a masseur and treat injuries; the subject needs a software application for sports massage, the subject requires
\end{abstract}


Journal of Sport Education (JOPE), 3 (2) 2021 - 104

Fekie Adila ${ }^{1^{*}}$, Rivan Saghita Pratama², Ni Putu Nita Wijayanti ${ }^{3}$, Oca Fernandes AF ${ }^{4}$, Mohammad Muhibi ${ }^{5}$, Ricky Fernando ${ }^{6}$

standardization and training from the pendorpowermassage.id massage platform provider; the subject requires standardization of the price of massage services from the platform provider. The conclusion of this study is the need to procure a pendorpowermassage.id in the Sports Coaching Education Study Program.

Keywords: business, sports, massage, masseur

How to Cite: Adila. F., Pratama, R.S., Wijayanti, N.P.N., AF, O.F., Muhibi, M., Fernando, R. (2021). Analisa kebutuhan platform pendorpowermassage.id sebagai solusi bagi para lulusan sarjana pendidikan kepelatihan olahraga. Journal of Sport Education (JOPE), 3 (2), 103-112. doi: http://dx.doi.org/10.31258/jope.3.2.103-112

Journal of Sport Education (JOPE) is an open access article under the CC-BY-SA 4.0

\section{PENDAHULUAN}

Mahasiswa pada program studi pendidikan kepelatihan olahraga dipersiapkan untuk menjadi guru dan pelatih professional di tingkat nasional bahkan internasional. Prospek peluang kerja mahasiswa lulusan fakultas ilmu olahraga khususnya program studi pendidikan kepelatihan olahraga adalah dapat menjadi praktisi maupun akademisi dalam dunia olahraga, tentunya dengan memiliki kompetensi di bidang keahlian masing-masing seperti: atlet, pelatih, private trainer, instruktur olahraga, sport terapis, manajer lembaga atau klub olahraga, sport event organizer, dan tenaga pendidik jasmani (Okta \& Hartono, 2020). Prospek peluang kerja yang dimiliki oleh mahasiswa program studi pendidikan kepelatihan olahraga cukup menjanjikan. Akan tetapi hal ini tidak sesuai dengan kondisi di lapangan. Berdasarkan data Universitas Riau (UNRI) misalnya, jumlah mahasiswa lulusan pendidikan kepelatihan olahraga sebanyak 80\% diantaranya bekerja sebagai stockis pada swalayan-swalayan. Hal ini membuktikan adanya ketidak relefanan antara keahlian yang dimiliki oleh alumni mahasiswa pendidikan kepelatihan olahraga dengan dunia kerja yang dimilikinya.

Kondisi yang ada di lapangan terkait jenjang karir yang diperoleh oleh alumni mahasiswa pendidikan kepelatihan olahraga menciptakan persepsi yang buruk di mata masyarakat. Kondisi ini diduga timbul akibat masih sedikitnya platform yang mampu mewadahi para alumni dari prodi pendidikan kepelatihan olahraga agar dapat memperoleh jenjang karir yang menjanjikan dan sesuai dengan skill yang dimilikinya sehingga hal ini memberikan dampak pada jumlah peminat jurusan pendidikan kepelatihan olahraga.

Menurut data yang ada, peminat pada jurusan pendidikan kepelatihan olahraga dapat dibilang sedikit. Hal ini dapat dilihat dari peminat pada jurusan Pendidikan kepelatihan olahraga di universitas-universitas yang menyediakan jurusan ini. Merujuk pada Universitas Riau sebagai contoh, jumlah peminat SBMPTN pada jurusan pendidikan kepelatihan olahraga pada tahun 2020 hanya berjumlah 75 orang dengan daya tamping pada tahun 2021 hanya sebanyak 33 orang. Jumlah ini merupakan jumlah terkecil dari semua jurusan yang ada di Universitas Riau (LTMPT, 2021). Hal ini tidak hanya terjadi di Universitas Riau.

Berdasarkan hasil Analisa yang ada, telah banyak hasil jurnalistik yang memaparkan, seperti media rencanamu (https://rencanamu.id/cari-jurusan/kesehatan/ilmukeolahragaan) yang banyak memaparkan terkait dunia perkuliahan, bahwa jurusan pendidikan kepelatihan olahraga merupakan salah satu dari jurusan-jurusan yang sepi peminat akan tetapi memiliki peluang karir yang menjanjikan kedepannya. Sayangnya tidak banyak yang mengetahui dan menyadari akan hal tersebut. Kondisi demikian diduga karena banyaknya lulusan jurusan pendidikan kepelatihan olahraga yang bekerja tidak sesuai pada bidang studinya, sehingga hal ini menciptakan persepsi yang tidak tepat pada jurusan pendidikan kepelatihan olahraga.

Disisi lain perkembangan teknologi informasi yang semakin pesat di era globalisasi saat ini tidak bisa dihindari dan justru harus dimanfaatkan se-optimal mungkin terutama dalam penyelesaian masalah khususnya pada bidang informasi dan komunikasi. Hal tersebut 
dikarenakan memadukan keilmuan merupakan suatu bentuk yang solutif untuk menyelesaikan suatu permasalahan yang tidak bisa diselesaikan dengan satu cabang keilmuan saja (Saputro, Wijaya, \& Dongoran, 2020). Pada penelitian ini penulis ingin menganilisa kebutuhan pada platform pendorpowermassage.id dalam hal ini adalah user yang berstatus sebagai mahasiswa maupun lulusan program studi pendidikan kepelatihan olahraga terhadap platform digital yang mampu mewadahi mereka untuk kemudian mengembangkan karirnya sesuai capaian pembelajaran kurikulum bidang studi yang telah ditekuni terutama dalam bidang sport massage.

Pengangkatan jenjang karir sebagai masseur pada solusi yang ditawarkan mengingat masih banyaknya kasus cidera yang tidak ditangani dengan tepat atau tidak ditangani oleh orang yang tepat yang sering kali terjadi terutama di Indonesia. Cidera merupakan hal yang dapat terjadi dimana saja dan kapan saja. Pengertian cidera sendiri adalah suatu akibat dari gaya-gaya yang bekerja pada tubuh atau sebagian dari pada tubuh dimana melampaui kemampuan tubuh untuk mengatasinya, gaya-gaya ini bisa berlangsung dengan cepat, atau jangka lama. Dapat dipertegas bahwa hasil suatu tenaga atau kekuatan yang berlebihan dilimpahkan pada tubuh atau sebagian tubuh sehingga tubuh atau bagian tubuh tersebut tidak dapat menahan atau menyesuaikan diri (Supriyadi \& Supriyono, 2014).

Kasus cidera paling banyak terjadi pada saat melakukan olahraga. Dalam hal fraktur tulang atau sendi, bagian yang cidera tersebut biasanya harus di-imobilisasi dan dibungkus dengan gips (Harsono, 2017). Cidera olahraga berat yang sering terjadi pada olahragawan adalah patah tulang yang dapat dibagi menjadi patah tulang terbuka dan tertutup. Pada kasus patah tulang, olahragawan harus berhenti dari pertandingan, dan secepat mungkin harus dibawa ke profesional masseur karena harus direposisi secepatnya. Reposisi yang dilakukan sebelum lima belas menit akan memberikan hasil memuaskan karena pada saat itu belum terjadi nyeri pada tulang (neural shock). Setelah reposisi bisa dipasang spalk untuk mempertahankan posisi dan sekaligus menghentikan pendarahan (Setiawan, 2011). Maka dengan banyaknya kondisi seperti ini yang terjadi, keberadaan profesional masseur sangat dibutuhkan.

Kemampuan profesional yang dimiliki oleh mahasiswa maupun lulusan program studi jurusan pendidikan kepelatihan olahraga akan sangat disayangkan jika tidak dioptimalkan dan dimanfaatkan dengan baik. Karena kondisi lingkungan saat ini, masih banyak ditemukan para lulusan pendidikan kepelatihan olahraga yang masih mengalami kesulitan dalam memperoleh pekerjaan dan masih banyak juga yang kemudian bekerja namun tidak sesuai dengan passion. Sementara pada program studi pendidikan kepelatihan olahraga, menjadi profesional masseur merupakan salah satu jenis lapangan pekerjaan yang sesuai dengan capaian pembelajaran jurusan Program studi.

Sistem informasi manajemen saat ini sudah tidak dapat dipisahkan lagi dari pengelolaan suatu organisasi modern. Di Indonesia sudah ada suatu platform yang mengakomodir yaitu Gojek. Pada platform Gojek tersedia menu Go Massage, dimana menu tersebut ialah mempertemukan expert dengan user yang membutuhkan, akan tetapi expert disini tanpa ada pembekalan suatu kompetensi fundamental di bidang sport massage dari platform Gojek.

Pendorpowermassage.id adalah platform berupa aplikasi yang menawarkan solusi bagi dua belah pihak utama, yaitu para mahasiswa atau sarjana lulusan program studi pendidikan kepelatihan olahraga untuk mendapatkan pekerjaan dalam bidang masseur yang kemudian dapat digunakan sebagai pekerjaan utama maupun sampingan dan juga bagi pihak yang membutuhkan professional masseur secara cepat dan tepat karena pada platform pendorpowermassage.id end user (dalam hal ini para pencari profesional masseur) dapat memilih sendiri profesional masseur yang diinginkan. 
Hingga saat ini belum ditemukannya platform serupa maupun penelitian serupa, khususnya di Indonesia yang menawarkan pekerjaan khusus sebagai profesional masseur bagi mahasiswa maupun lulusan program studi pendidikan kepelatihan olahraga sesuai dengan kompetensinya. Adapun urgensi penelitian ini adalah menganilisa kebutuhan platform pendorpowermassage.id dikarenakan beberapa kesenjangan yang terjadi diantaranya: 1) belum adanya platform yang mewadahi lulusan dan mahasiswa mengembangkan kompetensi di bidang sport massage; 2) belum adanya platform yang khusus memfasilitasi pengguna yang membutuhkan massage cidera; 3) lulusan jurusan pendidikan olahraga program studi pendidikan kepelatihan olahraga tidak mendapatkan lapangan pekerjaan yang linear dengan kurikulum capaian pembelajaran lulusan program studi; 4) lulusan dan mahasiswa jurusan pendidikan olahraga program studi pendidikan kepelatihan olahraga membutuhkan wadah untuk mengasah keterampilan di bidang sport massage; 5) mahasiswa jurusan pendidikan olahraga program studi pendidikan kepelatihan olahraga tidak dapat mengabdi pada masyarakat menggunakan keterampilannya; 6) banyaknya atlet / olahragawan / mahasiswa yang mengalami cidera ketika perkuliahan praktik berlangsung; 7) beberapa mahasiswa jurusan pendidikan olahraga program studi pendidikan kepelatihan olahraga membutuhkan pemasukan tambahan untuk menyelesaikan perkuliahannya.

\section{METODE}

Jenis penelitian ini adalah deskriptif kuantitatif, dengan menggunakan metode survei dan untuk teknik pengambilan data peneliti menggunakan kuesioner yang telah dibuat menggunakan platform google form untuk membantu alumni mahasiswa pendidikan kepelatihan olahraga mengisi kuesioner. Analisis deskriptif kuantitatif (QDA) sendiri digunakan untuk menggambarkan sifat dan intensitas sifat sensorik dari evaluasi tunggal suatu produk (Ng et al., 2012). Menurut Faelasofi (2017) analisis deskriptif kuantitatif dalam penelitian dapat berupa hasil persentase dari hasil survei. Sementara penelitian survei adalah penelitian yang mengambil sampel dari suatu populasi dan menggunakan kuisioner sebagai alat pengumpul data yang pokok (Koencoro dkk, 2013). Pentingnya kuesioner untuk penelitian survei menentukan keberhasilan penelitian yang berkaitan dengan kualitas data (data primer) (Sandjaja dan Purnamasari, 2017).

Sampel dari penelitian ini yaitu alumni mahasiswa dari Universitas Riau Fakultas Keguruan dan Ilmu Pendidikan Jurusan Pendidikan Olahraga Universitas Riau yang berasal dari angkatan 2016 atau yang saat ini sudah dinyatakan lulus pada periode 2020 dengan jumlah 24 alumni, dimana jumlah tersebut mewakili total mahasiswa angkatan 2016 yang berjumlah 120 orang. Penelitian dilaksanakan di lingkungan sekitar Fakultas Keguruan dan Ilmu Pendidikan, Universitas Riau. Namun, karena penelitian ini menggunakan google form maka dapat dilakukan dimana saja menggunakan media gadget dari mahasiswa. Waktu pelaksanaan penelitian pada tanggal 11 - 30 Maret 2021. Populasi dalam penelitian ini adalah alumni mahasiswa pendidikan kepelatihan olahraga dari angkatan 2016, dengan jumlah total populasi sebanyak 120 alumni. Dalam penelitian ini menggunakan teknik random sampling. Teknik Random Sampling yaitu teknik pengumpulan data dimana teknik pengambilan sampel dipilih acak dari populasi (Wahyudi dan Syah, 2019). Pengambilan sampel menurut (Arikunto, 2013), apabila subjek yang akan dijadikan sampel kurang dari 100 orang sebaiknya diambil seluruhnya, namun jika lebih besar dari 100 orang maka dapat diambil 10\%-15\% atau 20\%- 25\% atau lebih. melihat kondisi di lapangan dan juga efisiensi waktu yang digunakan untuk pengambilan sampel maka peneliti hanya mengambil $20 \%$ dari populasi yaitu sejumlah 24 sampel alumni mahasiswa pendidikan kepelatihan olahraga angkatan 2016, variabel pada penelitian ini yaitu tingkat kebutuhan alumni mahasiswa pendidikan 
kepelatihan olahraga terhadap pendorpowermassage.id. Instrumen penelitian ini berupa angket dalam bentuk google form yang berisi pertanyaan-pertanyaan tertulis dan diberikan secara langsung kepada subjek. Isi angket berupa pertanyaan yang terkait dengan kebutuhan para alumni terhadap lapangan kerja, kesiapan untuk turun lapangan menjadi masseur, dan kebutuhan platform pendorpowermassage.id sebagai penyedia jasa layanan untuk sport massage. Dalam penelitian ini teknik analisis data yang digunakan adalah statistik deskriptif. Statistik deskriptif sendiri merupakan analisa statistik yang digunakan untuk menganalisis data dengan cara mendeskripsikan atau menggambarkan data yang telah terkumpul sebagaimana adanya tanpa bermaksud membuat kesimpulan yang berlaku untuk umum atau generalisasi (Mahendra, 2015). Prosedur yang dilakukan diawali dengan menganalisis hasil angket setiap point. Setelah hasil didapatkan, data diolah dalam bentuk persentase sesuai prosedur yang berlaku. Kemudian hasil yang didapat dideskriptifkan atau digambarkan dan ditarik kesimpulan.

\section{HASIL}

Pada hasil dan pembahasan ini akan diberikan temuan penelitian berupa hasil dari angket per item untuk mengetahui informasi berkenaan dengan kebutuhan para lulusan atau alumni program studi kepelatihan olahraga terkait pengadaan platform pendorpowermassage.id dalam bentuk aplikasi android atau IOS. Item-item yang tersusun didahului oleh beberapa pertanyaan yang dirasa oleh penulis perlu dimunculkan agar informasi yang didapatkan tidak bersumber dari subjek yang kurang tepat. Tempat disini menyesuaikan dengan sasaran subjek yang akan diteliti, yaitu subjek yang sudah lulus atau di wisuda dari program studi pendidikan kepelatihan olahraga dimana para alumni tersebut sudah pernah mendapatkan mata kuliah massage. Adapun Item-item yang digunakan dalam pengambilan informasi pada penelitian ini berjumlah 5 item dengan rincian sebagai berikut. Item 1, Apakah subyek membutuhkan lapangan pekerjaan setelah lulus kuliah; item 2, Apakah subyek siap terjun ke lapangan untuk menjadi masseur dan mengani cidera; item 3, apakah subyek butuh aplikasi untuk sport massage; item 4, perlukah dibuat standarisasi ataupun training dari penyedia platform pendorpowermassage.id; item 5, perlukah dibuat standarisasi harga atau tarif dari penyedia jasa massage.

Berikut ini diberikan tabel hasil angket terhadap 24 orang alumni jurusan pendidikan olahraga prodi kepelatihan olahraga Universitas Riau tahun 2021. Informasi hasil angket dapat dilihat pada tabel 1 berikut ini:

Tabel 1. Tabel Persentase hasil angket

\begin{tabular}{ccccc}
\hline \multirow{2}{*}{ Item } & \multicolumn{2}{c}{ Sudah/Perlu } & \multicolumn{2}{c}{ Belum/Tidak Perlu } \\
\cline { 2 - 5 } & Jumlah & $\%$ & Jumlah & $\%$ \\
\cline { 2 - 5 } 1 & 24 & 100 & 0 & 0 \\
2 & 16 & 66,67 & 8 & 33,33 \\
3 & 24 & 100 & 0 & 0 \\
4 & 20 & 83,33 & 4 & 16,67 \\
5 & 24 & 100 & 0 & 0 \\
\hline
\end{tabular}

Selanjutnya terkait dengan sedikit tampilan platform yang ditawarkan dapat dilihat pada Gambar 1 dan Gambar 2 berikut. 
Journal of Sport Education (JOPE), 3 (2) 2021 - 108

Fekie Adila1 ${ }^{*}$, Rivan Saghita Pratama², Ni Putu Nita Wijayanti ${ }^{3}$, Oca Fernandes $\mathrm{AF}^{4}, \mathrm{Mohammad} \mathrm{Muhibi}^{5}$, Ricky Fernando $^{6}$
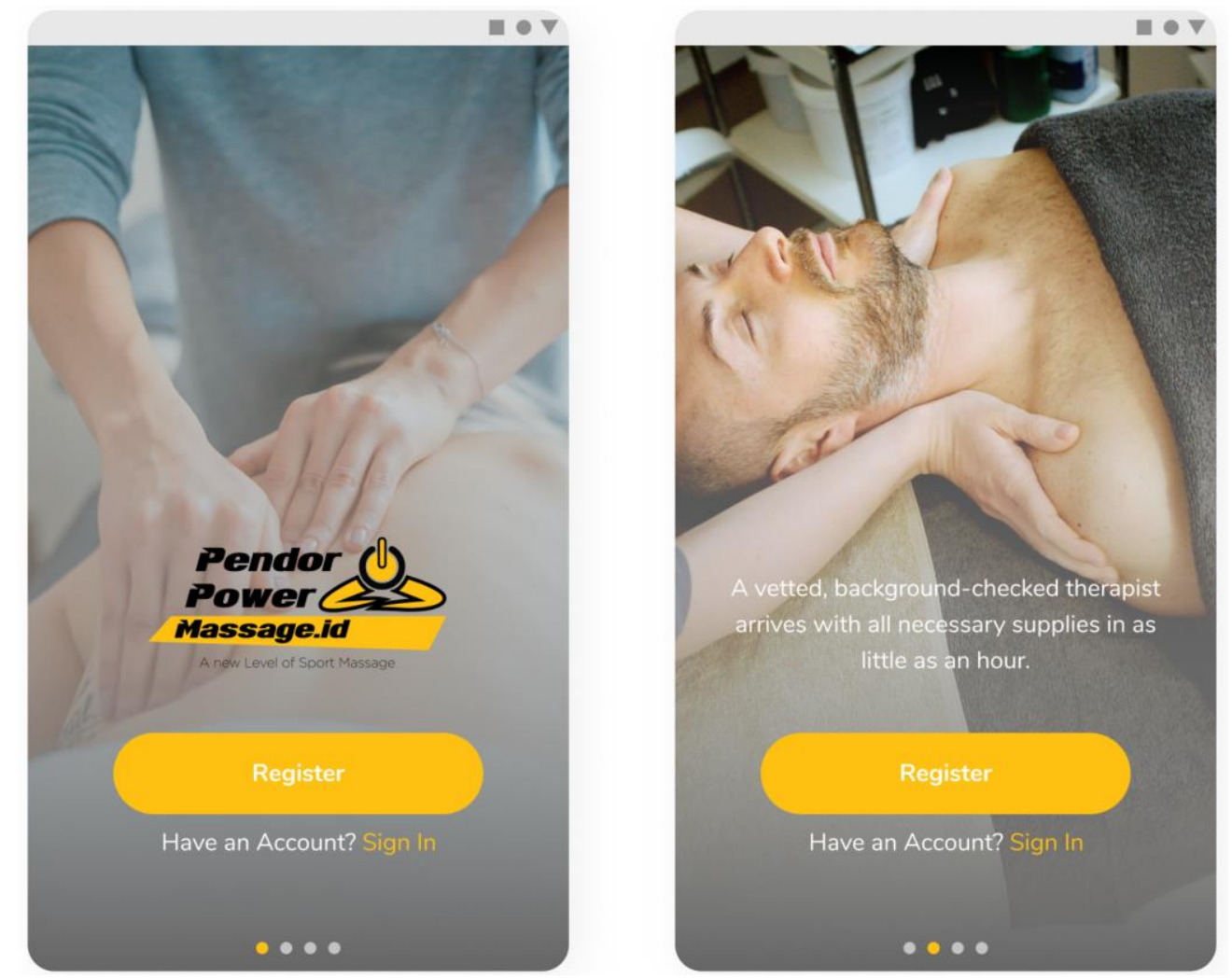

Gambar 1. Tampilan awal aplikasi Pendor Power Massage.id
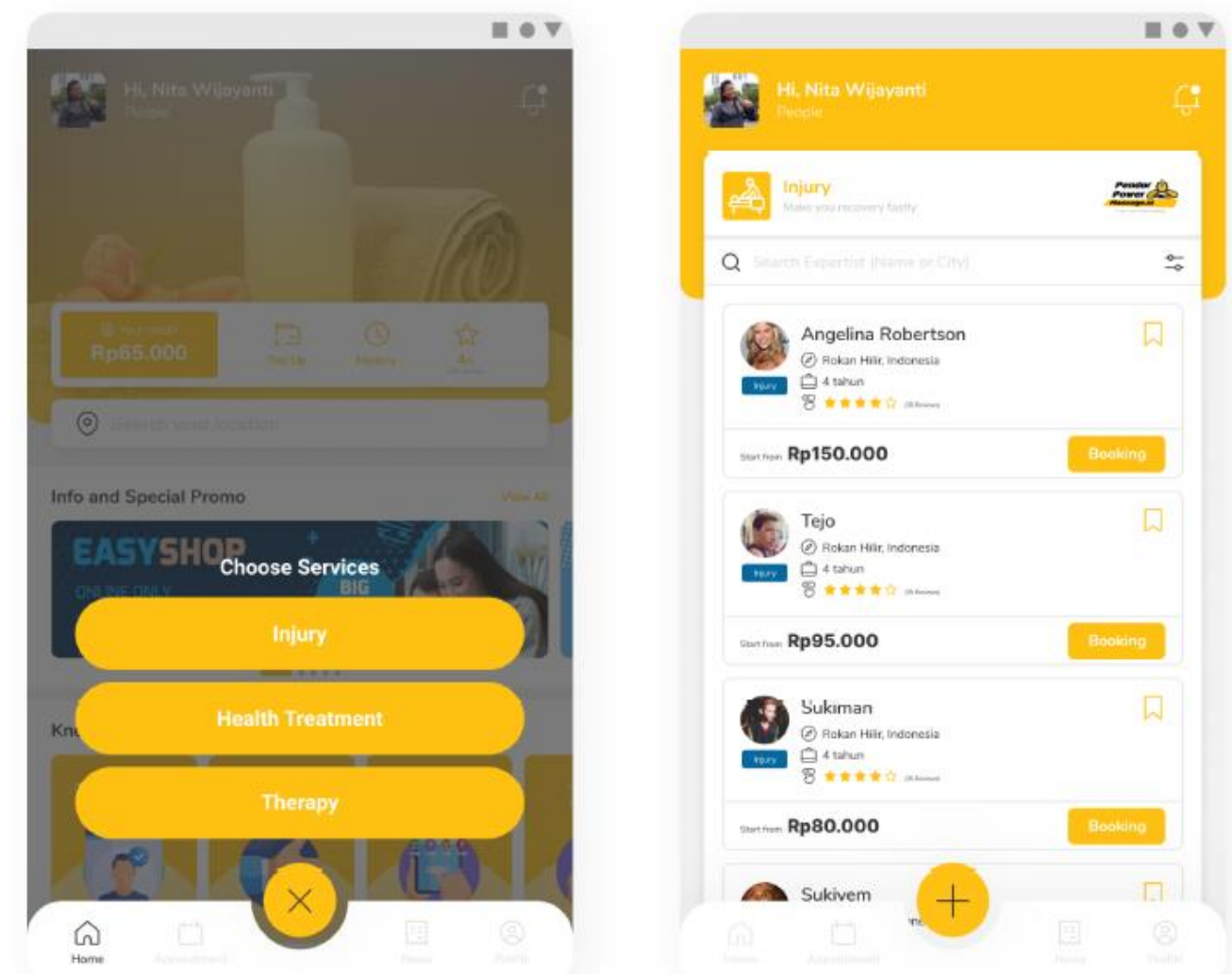

Gambar 2. Pemilihan pemesanan sesuai kebutuhan konsumen 


\section{Journal of Sport Education (JOPE), 3 (2) 2021 - 109}

Fekie Adila ${ }^{*}$, Rivan Saghita Pratama ${ }^{2}$, Ni Putu Nita Wijayanti ${ }^{3}$, Oca Fernandes $\mathrm{AF}^{4}, \mathrm{Mohammad} \mathrm{Muhibi}^{5}$, Ricky Fernando $^{6}$

\section{PEMBAHASAN}

Kebutuhan para alumni jurusan pendidikan olahraga prodi pendidikan kepelatihan olahraga Universitas Riau terhadap lapangan pekerjaan masih sangat tinggi, rasio tingkat kelulusan sarjana dengan lapangan pekerjaan yang tersedia tidak seimbang sehingga pengangguran tidak hanya yang tidak mempunyai pendidikan akan tetapi banyak juga yang mempunyai pendidikan ikut menjadi pengangguran (Wicaksono, 2011). Berdasarkan data BPS (2021) Tingkat Pengangguran Terbuka (TPT) Februari 2021 sebesar 6,26 persen, turun 0,81 persen poin dibandingkan dengan Agustus 2020 setelah sebelumnya mengalami kenaikan 0.88 persen pada Februari 2020.

Hasil analisis kebutuhan yang sudah dilakukan peneliti di lapangan yang melibatkan beberapa alumni, didapatkan informasi bahwa kebutuhan lapangan pekerjaan itu masih sangat tinggi khususnya bagi para mahasiswa yang baru lulus atau fresh graduate. Pada saat ini, kampus yang selalu memberikan bekal pendidikan entrepreneurship kepada calon lulusannya harusnya juga memberikan contoh dalam hal membuka peluang lapangan pekerjaan baru yang bisa mengakomodir para alumninya khususnya dari prodi Pendidikan kepelatihan olahraga yang nantinya platform pendorpowermassage.id bisa menjadi solusi terkait tingginya kebutuhan lapangan pekerjaan bagi alumni.

Berdasarkan data yang sudah dipaparkan pada bab hasil sebelumnya, data menunjukkan bahwa subjek yaitu alumni jurusan pendidikan olahraga prodi pendidikan kepelatihan olahraga Universitas Riau rata-rata siap terjun ke lapangan untuk menjadi masseur akan tetapi ada beberapa alumni juga yang belum siap untuk terjun kelapangan menjadi masseur, hal ini berkaitan erat dengan kompetensi mereka. (Sanghi, 2007) menyampaikan bahwa kompeten merupakan keahlian dan standar performa yang dicapai oleh seseorang. Sementara itu kompetensi dikatakan sebagai perilaku yang diadopsi ketika menampilkan kompetennya (keahliannya). Hal ini menunjukkan bahwa tingkat kompetensi mahasiwa setelah mengikuti mata kuliah massage tidak semua mahir akan tetapi ada juga mahasiswa yang hanya mengikuti perkuliahan sekedar formalitas saja. Oleh karena itu perlu adanya penekanan atau tugas tambahan bagi mahasiswa agar bersungguh-sungguh dalam mengikuti kuliah massage yang nantinya bisa menjadi bekal dan lapangan pekerjaan bagi mereka.

Selanjutnya berkaitan dengan kebutuhan aplikasi untuk sport massage, para subjek seluruhnya mengatakan butuh suatu aplikasi yang bisa menaungi mereka dalam pekerjaan sport massage. Dalam hal ini yang dimaksud dari para alumni adalah ada sebuah alat atau rancangan sistem yang memudahkan orang-orang untuk mencari masseur dan juga para masseur pun tidak susah-susah untuk mencari customer. Para programmer, dengan bahasa program, membuat otomatisasi, pemasukan data, pemrosesan data, dan pembuatan laporan (input, data processing, output), sehingga pekerjaan rutin yang dahulu melibatkan banyak orang kemudian dapat dilakukan dengan lebih efisien oleh operator komputer (Tantra, 2012). Disisi lain jumlah pengguna smartphone terus mengalami peningkatan. Hampir seluruh aktifitas dan kebutuhan manusia dijalankan dari sebuah genggaman. Catriana (2020) memaparkan bahwa pihak Komenkominfo memaparkan bahwa terdapat 338,2 juta jiwa penduduk Indonesia yang telah menggunakan smartphone, dan angka ini diprediksi akan terus meningkat $17 \%$ setiap tahunnya. Badan Pusat Statistika (2019) juga menunjukkan data adanya peningkatan kepemilikan telepon seluler terus mengalami peningkatan seiring dengan peningkatan kepemilikan komputer dan pemanfaatan internet. Dengan demikian menjadi peranan penting bagi kita untuk dapat terus beradaptasi dengan dunia teknologi yang semakin canggih. Dengan ramainya smartphone yang hampir setiap orang punya diharapkan aplikasi ini bisa terinstal di android ataupun IOS sehingga 


\section{Journal of Sport Education (JOPE), 3 (2) 2021 - 110}

Fekie Adila ${ }^{*}$, Rivan Saghita Pratama², Ni Putu Nita Wijayanti ${ }^{3}$, Oca Fernandes $\mathrm{AF}^{4}, \mathrm{Mohammad} \mathrm{Muhibi}^{5}$, Ricky Fernando $^{6}$

memudahkan setiap orang dalam mencari jasa terapi massage. Selain itu para alumni yang baru luluspun tidak susah-susah mencari lapangan pekerjaan jika mereka sudah siap untuk menjadi seorang terapis dari pendorpowermassage.id.

Terkait dengan perlu tidaknya dibuat standarisasi ataupun training dari penyedia platform pendorpowermassage.id 83,33\% subjek menjawab perlu dikarenakan dalam platform pendorpowermassage.id ada beberapa fitur layanan antara lain Injury (cidera), health treatment (sport massage), dan therapy (latihan untuk terapi ataupun penguatan otot). Dengan bekal yang didapat para alumni saat kuliah sebenarnya untuk penyedia paltform ini tidak perlu melakukan training lagi seperti yang diungkapkan sebagian kecil dari subjek dari penelitian ini yaitu cuma 16,67\%. Mereka yang menjawab tidak memerlukan training lagi dikarenakan sudah merasa cukup dengan ilmu yang mereka miliki untuk memulai bekerja. Sedangkan untuk sebagian besar subjek menginginkan ada training ataupun pendalaman materi lagi dikarenakan mereka merasa bahwa apa yang mereka dapatkan dirasa masih kurang karena hanya 1 (satu) semester saja. Perlu adanya pendalaman materi yang intens selama 1 (satu) bulan atau lebih dengan instruktur yang profesional. Pada platform pendorpowermassage.id sudah ada standar operasional prosedur (SOP) yang harus dijalankan untuk para terapis atau mahasiswanya yang bergabung.

Selanjutnya, berhubungan perlu atau tidak dibuat standarisasi harga atau tarif dari penyedia jasa massage, seluruh subjek menyatakan bahwa perlu adanya persamaan harga dari semua terapis atau masseur. Harga merupakan salah satu variabel dari pemasaran atau penjualan selama harga tersebut terjadi atas dasar keadilan dan suka sama suka antara penjual dan pembeli (Ernawati, 2017). Jika harga jasa massage sudah sama maka customer tinggal memilih terapis mana yang akan mereka gunakan. Disisi lain penyedia platform pun lebih mudah mengontrol dalam penggajian terapis mereka

\section{SIMPULAN}

Berdasarkan hasil penelitian dan dapat disimpulkan bahwa platform pendorpowermassage.id merupakan suatu hal yang diperlukan. Adanya platform ini merupakan sebuah langkah dalam rangka memberikan solusi guna membuka lapangan pekerjaan bagi para alumni khususnya prodi pendidikan kepelatihan olahraga sebagai masseur. Mahasiswa yang sudah dibekali ketrampilan saat kuliah tidak susah dalam mencari kerja dan masyarkat luaspun tidak susah ataupun khawatir dalam mencari masseur yang profesional dan sudah terlatih secara formal dalam perguruan tinggi.

\section{DAFTAR PUSTAKA}

Arikunto, S. (2013). Manajemen Penelitian. Jakarta: Rineka Cipta.

Badan Pusat Statistika. (2019). Statistik Telekomunikasi Indonesia 2019. Jakarta. BPS-Statistika Indonesia

Badan Pusat Statistika. (2021). Tingkat Pengangguran Terbuka (TPT). Jakarta. BPS-Statistika Indonesia

Catriana, E. (2020). Pengguna Internet di Indonesia Naik 17 Persen Per Tahun. Kompas. Jakarta

Davis H.L., Alabed S., Chico T. J. A. (2020) Effect of sports massage on performance and recovery: a systematic review and meta-analysis. BMJ Open Sport \& Exercise Medicine. https://doi.org/10.1136/bmjsem-2019-000614 


\section{Journal of Sport Education (JOPE), 3 (2) 2021 - 111}

Fekie Adila ${ }^{*}$, Rivan Saghita Pratama ${ }^{2}$, Ni Putu Nita Wijayanti ${ }^{3}$, Oca Fernandes $\mathrm{AF}^{4}$, Mohammad Muhibi ${ }^{5}$, Ricky Fernando $^{6}$

Ernawati, E. (2017). Analisis Mekanisme Penetapan Harga Jual Produk Dalam Upaya Meningkatkan Pendapatan Ekonomi Rumah Tangga Menurut Perspektif Ekonomi Islam (Studi pada Siger Roemah Batik Kecamatan Kemiling Bandar Lampung) (UIN Raden Intan Lampung). Retrieved from http://repository.radenintan.ac.id/id/eprint/1166

Faelasofi, R. (2017). Identifikasi Kemampuan Berpikir Kreatif Matematika Pokok Bahasan $\begin{array}{lllll}\text { Peluang. } & \text { Jurnal } & \text { Edumath } & 3 & \text { (2). }\end{array}$ https://ejournal.umpri.ac.id/index.php/edumath/article/view/460/264

Gonenc, Ilknur Muneever, Terzioglu, Fusun (2020) Effect of Massage and Acupressure on Relieving Labor Pain, Reducing Labor Time, and Increasing Delivery Satisfaction. Journal of Nursing Research. Vol 28 -Issue 1- $p$ e68. https://journals.lww.com/jnrtwna/Fulltext/2020/02000/Effects_of_Massage_and_Acupressure_on_Relieving.10.aspx

Harsono. (2017). Kepelatihan olahraga. Teori dan metodologi. Bandung: PT. Remaja Rosdakarya.

Jiang Z, Zhang H, Yu T, Du Y, Qian Z, Chang F (2020). Musculoskeletal Combined with Electromyography in the Diagnosis of Massage-Inducted Lateral Plantar Nerve Injury: A $\begin{array}{lllll}\text { case } & \text { report. } & \text { Medicine, } & 99 & \text { (28), }\end{array}$ https://doi.org/10.1097/MD.0000000000021130

Koencoro, G. D., Al Musadieq, M., Susilo, H., (2013). Pengaruh Reward Dan Punishment Terhadap Kinerja. Jurnal Administrasi Bisnis 5(2). 411-418. http://administrasibisnis.studentjournal.ub.ac.id/index.php/jab/article/view/236/411

Lembaga Tes Masuk Perguruan Tinggi. (2021). Daftar Prodi SBPMTN Universitas Negri Riau 2021. Jakarta. LTMPT. https://sidata-ptn.ltmpt.ac.id/ptn_sb.php?ptn=131

Mahendra, I. (2015). Analisa Penerimaan Pengguna Sistem Informasi Koperasipada Koperasi Karyawan Budi Setia Jakarta Dengan Technology Acceptance Model. Jurnal Pilar Nusa Mandiri,

70-80. http://ejournal.nusamandiri.ac.id/index.php/pilar/article/view/415/365

Miake-lye I. M, Mak S, Lee J, et al (2019) Massage for Pain: An Evidence Map. Journal of Alternative and Complementary Medicine. https:// doi.org/10.1089/acm.2018.0282

Ng, M., Lawlor, J. B., Chandra, S., Chaya, C., Hewson, L., Hort, J. (2012). Using Quantitative Descriptive Analysis And Temporal Dominance of Sensations Analysis As Complementary Methods For Profiling Commercial Blackcurrant Squashes. Food Quality and Preference, 25. 121-134

Okta, R. P., \& Hartono, S. (2020). Tingkat pengetahuan penanganan cidera olahraga pada mahasiswa. 8(2), 101-108.

Sandjaja, I. E., Purnamasari, D. (2017). Perancangan Kuisioner Survei Galangan. Technology Science and Engineering Journal, 1(1). 27-33. file:///C:/Users/ASUS/Downloads/204535-1-PB.pdf

Sanghi, S. (2007). The handbook of competency mapping: Understanding, designing and 


\section{Journal of Sport Education (JOPE), 3 (2) 2021 - 112}

Fekie Adila ${ }^{*}$, Rivan Saghita Pratama ${ }^{2}$, Ni Putu Nita Wijayanti ${ }^{3}$, Oca Fernandes AF ${ }^{4}$, Mohammad Muhibi ${ }^{5}$, Ricky Fernando ${ }^{6}$

implementing competency models in organizations. In The Handbook of Competency Mapping: Understanding, Designing and Implementing Competency Models in Organizations. https://doi.org/10.4135/9788132108481

Saputro, D. P., Wijaya, M. R. A., \& Dongoran, M. F. (2020). Analysis of Software Requirement Management Results for Physical Tests of Adolescent Pencak Silat Fighting Categories. JUARA : Jurnal Olahraga. https://doi.org/10.33222/juara.v5i1.842

Setiawan, A. (2011). Faktor Timbulnya Cidera Olahraga. Media Ilmu Keolahragaan Indonesia, 1(1), 94-98. https://doi.org/10.15294/miki.v1i1.1142

Supriyadi, H., \& Supriyono. (2014). Analisis Cidera Olahraga Dalam Aktivitas Pendidikan Jasmani Pada Siswa SMA Negeri 1 Nalumsari. Journal of Physical Education, Sport, Health and Recreation, 6(1), 45-52. Retrieved from http://journal.unnes.ac.id/sju/index.php/peshr

Tantra, R. (2012). Manajemen Proyek Sistem Informasi, CV. Andi Offset, Yogyakarta.

Wahyudi, R., Syah, N. (2019). Hubungan Minat Menjadi Guru Dengan Kesiapan Mengajar Mahasiswa Prodi Pendidikan Teknik Bangunan. Jurnal Teknik Bangunan 6(1). 1-5. file://C:/Users/ASUS/Downloads/104955-32170-1-SM.pdf

Wicaksono, K. C. B. (2011). Mempersiapkan Lulusan Sarjana menjadi Pencipta Lapangan Pekerjaan. Binus Business Review, 2(1), 370. https://doi.org/10.21512/bbr.v2i1.1143

Xing X. X, Zheng M. X, Hua X. Y, Ma S. J, Ma Z. Z, Xu J. G (2021) Brain Plasticity After Peripheral Nerve Injury Treatment with Massage Therapy Based on Resonance Imaging. Neural Regeneration Research. vol. 16. (2), 388-393. https: //doi.org/104103/16735374.290912 